cular' adsorption theory of the author, Emmett and Teller. This theory takes account of the fraction of surface covered and the heat of adsorption, in each of a large number of layers on the surface; in the layers beyond the first, the heat of adsorption is taken, as a first approximation, as equal to the heat of condensation to bulk liquid. Most of the numer: ous forms which the adsorption isotherms can take are explained, quantitatively, by this theory, with allowance for capillary condensation in the pores : it marks a very great advance on any preceding theories, and covers the great bulk of all possible cases of adsorption.

In the discussion of the structure of porous adsorbents, some of the theories quoted, notably those dealing with the apparent density of adsorbents such as charcoal, and the hysteresis sometimes found in adsorption, might perhaps be considerably clarified if more attention were paid to the contact angle between the substances adsorbed, when liquid, and the solid adsorbent. It would seem much more likely that the contact angle governs the extent of penetration of liquid into minute pores than the viscosity; indeed, I think that possibly this angle is a dominating factor in the values found for the apparent density, measured by the displacement of liquids. Perhaps also the well-known hysteresis of the contact angle, coming into play as an 'advancing' angle when capillary spaces are being filled with adsorbate, and a 'receding' angle, always smaller than the advancing angle, during desorption and emptying of capillaries, is largely responsible for adsorption hysteresis. The rather far-fetched theory which claims that pores in some adsorbents resemble 'ink-bottles' in shape might prove superfluous if attention were paid to this hysteresis of contact angles.

The treatment of the state of the adsorbed film is cautious ; the author does not commit himself for, or against, recent theories which regard the adsorbed layer as possessing most of the properties of a twodimensional gas even to the extent that the outward surface pressure of these gases can cause expansion of the adsorbent. Neither are the discontinuities in the adsorption isotherms, now based on experimental evidence from a number of sources, treated, except as a curious phenomenon not at present to be integrated with the rest of the theory. This caution would, however, seem well justified in the present state of knowledge.

The author is to be congratulated on a very fine account of a complex subject, more complex perhaps than most non-specialists will have suspected. $\mathrm{He}_{\mathrm{e}}$ has given a very learned and well-balanced picture of practically all the important theories that have been proposed, and there are many of them. It is impartial-perhaps for some tastes a trifle too impartial, for the book has, in places, to be very carefully read to ascertain what the author's own views are; but the reader is always given very full material on which to base his own judgment.

The preface warns that we shall have to wait some time for the second volume, which is to deal with chemical adsorption. This is tantalizing, for one who can give such a stimulating account of what many people would expect to be the less interesting half of the subject should have something enthralling to say about the other half. He does, however, let fall one provocative remark, to whet our appetite for what is still to come, saying on p. 10, "there is some opposition even to-day to accepting the concept of activated adsorption". I myself, being still somewhat sceptical that slow adsorption can legitimately be ascribed to an energy of activation in the chemisorption of gases in the first layer, look forward impatiently to the author's promised marshalling of the evidence in its favour. It is a very important point of theory, and no one can be better fitted than the author for bringing all the evidence into proper focus ; his knowledge is unsurpassed, and his fairness as an expositor seldom equalled. N. K. ADAM.

\section{AVIATION MEDICINE}

\section{A Bibliography of Aviation Medicine and Supple- ment}

By Phebe Margaret Hoff, Ebbe Curtis Hoff and John Farquhar Fulton. (Publication No. 9, Historical Library, Yale Medical Library.) Pp. xiv+109. (Washington, D.C.: National Research Council, 1944.) n.p.

A VIATION medicine has become a subject of A prime practical importance in the present War. It is a subject in which the basic data from many fields of physiology are required in new applications. The compilation of a bibliography of aviation medicine is therefore a work of great value to those interested in this field. A large volume of work done in Service laboratories is not included, as this has not yet been published in open form; this is often less due to secrecy provisions than to the extreme preoccupation of the research workers with urgent operational problems. For, while many of the applications of physiology to aviation carried out in Service laboratories are at present restricted by secrecy considerations, the scientific basis of most of these rests on fundamental physiology often published many years before the War; this bibliography covers the field in all its ramifications. Only a few applied sections are seriously incomplete and must remain so until after the War.

This Bibliography, first published in 1942, is now followed by a supplement, mostly of work published since 1940 .

The classification by subject-matter is convenient, and all references are given numbers used for reference in cross-indexing at the foot of each subsection. An author index is included.

The section "Special Physiology of Aviation and Conditions Simulating Flight" occupies nearly half the volume and is divided into twenty-three physiological divisions further subdivided.

The Bibliography is comprehensive and includes historical works and accounts of early balloon and mountain ascents where these contained any pertinent matter.

Research on the effects of altitude may be divided historically into two parts, from Robert Boyle to Paul Bert, and Paul Bert to the present. Robert Boyle subjected animals to low pressure and recorded seeing a bubble in the eye of a viper when exposed to low pressure, and so might be considered the discoverer of decompression sickness. Modern research dates from Bert, who laid the main foundations of modern knowledge in his great work "La Pression Barométrique", published in 1878.

The book is excellently produced, and the arrangement could well serve as a model of bibliography.

B. H. C. Matthews. 